\section{Fruit of Autumn Olive: A Rich Source of Lycopene}

Ingrid M. Fordham ${ }^{1}$

Fruit Laboratory, Plant Sciences Institute, U.S. Department of Agriculture, Agricultural Research Service, Beltsville, MD 20705-2350

Beverly A. Clevidence and Eugene R. Wiley

Phytonutrients Laboratory, Beltsville Human Nutrition Research Center, U.S. Department of Agriculture, Agricultural Research Service, Beltsville, MD 20705-2350

\section{Richard H. Zimmerman ${ }^{2}$}

Fruit Laboratory, Plant Sciences Institute, U.S. Department of Agriculture, Agricultural Research Service, Beltsville, MD 20705-2350

Additional index words. Elaeagnus umbellata, carotenoids, antioxidant, erosion control

Abstract. Autumn olive (Elaeagnus umbellata Thunb.) has edible fruit with brilliant red or yellow pigmentation. An analysis of the pigment in fruit of five cultivars and six naturalized plants showed that the berries contain lycopene, $\alpha$-cryptoxanthin, $\beta$-cryptoxanthin, $\beta$-carotene, lutein, phytoene, and phytofluene. The lycopene content per $100 \mathrm{~g}$ ranged from 15 to $54 \mathrm{mg}$ in fresh fruit from the naturalized plants and from 17 to $48 \mathrm{mg}$ in the four cultivars with red-pigmented fruit. A cultivar with yellow fruit had only $0.47 \mathrm{mg} / 100 \mathrm{~g}$ fresh fruit. In contrast, fresh tomato fruit, the major dietary source of lycopene, has a lycopene content per $100 \mathrm{~g}$ of $\approx 3 \mathrm{mg}$. This newly identified source of lycopene may provide an alternative to tomato as a dietary source of lycopene and related carotenoids.

Autumn olive (Fig. 1), a shrub native to southern Europe and western and central Asia, was introduced to the United States around 1830 as an ornamental plant (Dirr, 1983). It is valued for its ability to prevent erosion, to fix nitrogen, and to attract wildlife (Zarger, 1980), and has been used to enhance certain types of agroforestry (Campbell and Dawson, 1989). Although the fruit is eaten in Asia (Parmar and Kaushal, 1982; Tanaka, 1976), there are only a few references to human consumption of autumn olive in the United States (Darrow and Yerkes, 1937; Reich, 1991). The abundant, sweet-tart fruit can be used for preserves, condiments, fruit rolls, juice, flavoring, and other food products.

The fruit of autumn olive is notable for its typical deep-red color. The identity of the pigment, to our knowledge, has not been reported, but it is insoluble in water or alcohol, suggesting that carotenoids rather than anthocyanins provide the color. We analyzed autumn olive fruit, both naturalized and cultivated, and found the fruit to be a particularly

Received for publication 12 Dec. 2000. Accepted for publication 10 Apr. 2001. We thank Fred Khachik for providing samples of phytoene and phytofluene. We also thank Annie and Hector Black, of Hidden Springs Nursery, Cookeville, Tenn., for providing fruit samples of five cultivars of autumn olive. The cost of publishing this paper was defrayed in part by the payment of page charges. Under postal regulations, this paper therefore must be hereby marked advertisement solely to indicate this fact.

${ }^{1}$ To whom reprint requests should be addressed. E-mail address: fordhami@ba.ars.usda.gov

${ }^{2}$ Retired. rich source of lycopene, a carotenoid widely believed to protect against myocardial infarction (Kohlmeier et al., 1997) and various forms of cancer (Clinton, 1998), including prostate cancer (Giovannucci et al., 1995).

\section{Materials and Methods}

In Fall 1999, ripe berries of five cultivars of autumn olive from Hidden Springs Nursery, Cookeville, Tenn., were shipped fresh, with fruit from each selection collected in a separate plastic bag, frozen upon receipt, and stored at $-80{ }^{\circ} \mathrm{C}$. One sample of each selection was extracted and analyzed.
Fig. 1. Fruit of autumn olive.
Ripe berries of six selected naturalized plants were picked in Howard County, Md., also in Fall 1999, placed in individual plastic bags, frozen, and stored at $-80^{\circ} \mathrm{C}$. One sample of each was extracted and analyzed.

The whole berries were treated by a procedure optimized for the extraction of carotenoids (Khachik et al., 1992). In brief, $5 \mathrm{~g}$ of fruit were mixed with $10 \mathrm{~mL} \cdot \mathrm{g}^{-1}$ tetrahydrofuran (THF) containing $0.05 \%$ butylated hydroxytoluene (BHT), 10\% (by weight) magnesium carbonate, and $15 \%$ (by weight) celite, added to a precooled blender (Omni-Mixer; Omni International, Gainesville, Va.), and blended for 20 min on medium speed in an ice jacket. The mixture was filtered through Whatman No. 1 paper on a Büchner funnel and the solid material was re-extracted twice, yielding a residue devoid of pigments. The filtrates were combined and the volume reduced under vacuum on a rotary evaporator. The concentrate was dissolved in $25 \mathrm{~mL}$ methanol and partitioned into methylene chloride and saturated salt water in a separatory funnel; the organic layer was removed and the water layer washed with methylene chloride. The organic layers were dried over anhydrous sodium sulfate, filtered, and the volume reduced on a rotary evaporator to near dryness. The concentrate was dissolved and the volume brought to $100 \mathrm{~mL}$ with methylene chloride containing $0.01 \%$ BHT. To ensure accuracy of the measurements, four dilutions of each extract were analyzed and evaluated for linearity. The dilution factors were $1,2,25$, and 50 for all extracts; values derived from the lesser dilutions were used to quantify carotenoids other than lycopene. Aliquots $(0.4 \mathrm{~mL})$ of each dilution were added to tubes containing the internal standard $\left(0.4 \mathrm{~mL} \beta\right.$-apo- $8^{\prime}$-carotenal $)$, then dried under nitrogen. The residues were dissolved in $0.4 \mathrm{~mL}$ of high-performance liquid chromatography (HPLC) solvent (mobile phase) and $50 \mu \mathrm{L}$ was injected onto a 5$\mu \mathrm{m}$ reverse-phase $\mathrm{C} 18$ analytical column (Microsorb-MV; Varian Analytical Instruments, Walnut Creek, Calif.), $250 \mathrm{~mm} \times 4.6$ $\mathrm{mm}$, protected by a $5-\mu \mathrm{m}$ guard cartridge, 30

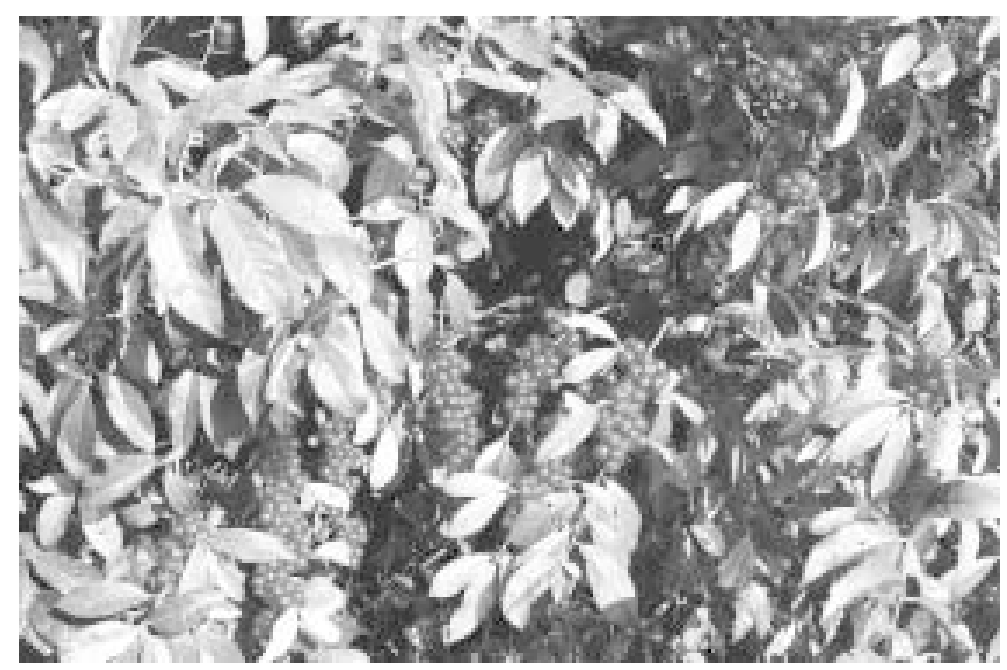


Table 1. Carotenoid content of fruit, on wet weight basis, from naturalized and cultivated plants of autumn olive.

\begin{tabular}{|c|c|c|c|c|c|c|c|c|c|c|}
\hline & Lycopene & Lycopene & Lutein & $\alpha$-Cryptoxanthin & $\beta$-Cryptoxanthin & $\alpha$-Carotene & $\beta$-Carotene & Phytofluene & Phytoene & $\begin{array}{c}\text { Total } \\
\text { carotenoids }\end{array}$ \\
\hline $\begin{array}{l}\text { Naturalized plants: } \\
\text { range }(n=6)\end{array}$ & $\begin{array}{c}--\%^{\mathrm{z}}- \\
82\end{array}$ & $\begin{array}{c}---- \\
38,232 \\
15,090 \\
-53,966\end{array}$ & $\begin{array}{c}---- \\
156 \\
106-288\end{array}$ & $\begin{array}{c}------ \\
2,921 \\
962-4432\end{array}$ & $\begin{array}{c}--\frac{---\mu g}{4,374} \\
1,658-6,603\end{array}$ & $\begin{array}{c}1100 \mathrm{~g}_{-}-- \\
46 \\
31-68\end{array}$ & $\begin{array}{c}----- \\
384 \\
230-599\end{array}$ & $\begin{array}{c}----- \\
103 \\
49-174\end{array}$ & $\begin{array}{c}--\frac{-}{650} \\
338-867\end{array}$ & $-\frac{---}{46,866}$ \\
\hline \multicolumn{11}{|l|}{ Cultivars: } \\
\hline Delightful & 82 & 29,682 & 67 & 2,379 & 3,590 & 14 & 172 & 77 & 391 & 36,372 \\
\hline Jewel & 81 & 48,334 & 92 & 4,169 & 6,167 & 32 & 248 & 105 & 505 & 59,652 \\
\hline Brilliant Rose & 72 & 29,591 & 49 & 3,976 & 7,003 & 5 & 103 & 108 & 521 & 41,356 \\
\hline Sweet 'n' Tart & 72 & 17,874 & 56 & 2,306 & 4,068 & 6 & 29 & 80 & 394 & 24,813 \\
\hline Charlie's Golden & 12 & 471 & 101 & 52 & 96 & 22 & 382 & 172 & 2,596 & 3,892 \\
\hline
\end{tabular}

${ }^{ }$Lycopene as a percentage of total carotenoids.

$\mathrm{mm} \times 4.6 \mathrm{~mm}$. Carotenoids were eluted under isocratic conditions within $30 \mathrm{~min}$ at a flow rate of $0.80 \mathrm{~mL} \cdot \mathrm{min}^{-1}$ on a HPLC system with diode array detection (Hewlett Packard Series 1050, Palo Alto, Calif.). The mobile phase consisted of $65 \%$ acetonitrile, $25 \%$ methylene chloride, $10 \%$ methanol, $1 \mathrm{~g} \cdot \mathrm{L}^{-1} \mathrm{BHT}$, and 0.1 $\mathrm{mL} \cdot \mathrm{L}^{-1}$ of $N, N$-diisopropylethylamine (Aldrich Chemical Co., Milwaukee). Solvents were HPLC grade (Fisher Scientific, Pittsburgh) and used without further purification. The carotenoids were quantified following simultaneous detection at 450, 350, and $300 \mathrm{~nm}$. Reference samples of carotenoids used for calibration of the HPLC system were isolated from natural sources or purchased from Sigma Chemical Co. (St. Louis). For each carotenoid of each sample, values from the individual dilutions were scaled to the original volume and averaged using only those dilutions that fell within the absorbance range of the calibrated standards. The precision and accuracy of the HPLC system was verified using Standard Reference Material 968b (National Institute of Standards and Technology, Gaithersburg, Md.).

\section{Results and Discussion}

Lycopene was the dominant carotenoid in fruit from both naturalized autumn olive and four of five cultivars of autumn olive assessed in this study (Table 1). In red-pigmented berries, lycopene accounted for $72 \%$ to $82 \%$ of the total carotenoids. The lycopene content per $100 \mathrm{~g}$ ranged from 15 to $54 \mathrm{mg}$ in fresh fruit from the naturalized plants and from 18 to 48 $\mathrm{mg}$ in fruit from the four cultivars with redpigmented fruit. An exception was 'Charlie's Golden', an anomalous, yellow-pigmented cultivar, which was relatively low in total carotenoids. This cultivar contained only 0.47 $\mathrm{mg}$ of lycopene per $100 \mathrm{~g}$ fresh weight of fruit (12\% of total carotenoids) but contained high concentrations of phytoene, a precursor of lycopene. Additionally, red-fruited types contained high levels of $\alpha$ - and $\beta$-cryptoxanthin. The $\beta$-cryptoxanthin content of these varieties was $\approx 10$ times higher than the $\beta$-cryptoxanthin content of orange and tangerine (U.S. Dept. of Agriculture, Agricultural Research Service; and Univ. of Minnesota, Nutrition Coordinating Center, 1998), which are major sources of this carotenoid in the U.S. diet (Chug-Ahuja et al., 1993). Autumn olive fruit also contained small amounts of $\beta$-carotene, lutein, and phytofluene.

Tomato products are the dominant source of dietary lycopene in the United States, accounting for more than $80 \%$ of lycopene intake (Clinton, 1998). Watermelon [Citrullus lanatus (Thunb.) Matsum. \& Nakai], guava (Psidium guajava L.), papaya (Carica papaya L.), and pink grapefruit (Citrus $\times$ paradisi Macf.) are other sources of lycopene (Clinton, 1998; Mangels et al., 1993), but provide a relatively minor proportion of the intake. In contrast, other common dietary carotenoids, such as $\beta$-carotene and lutein, are found in a variety of fruits and vegetables.

Autumn olive fruit is similar to tomato in that both fruits are rich in lycopene and contain other carotenoids, including $\beta$-carotene, phytoene, and phytofluene, but lycopene concentrations of red autumn olive fruit (15 to 54 $\mathrm{mg} / 100 \mathrm{~g}$ ) are considerably higher than nutrient database values (U.S. Dept. of Agriculture, Agricultural Research Service; and Univ. of Minnesota, Nutrition Coordinating Center, 1998) for fresh tomato fruit $(3 \mathrm{mg} / 100 \mathrm{~g})$, and are similar to that of tomato paste $(29 \mathrm{mg} / 100$ $\mathrm{g})$. Thus, if lycopene alone, or in synergy with other carotenoids, is responsible for the purported cancer prevention properties of tomato (Clinton, 1998), the autumn olive fruit, a new dietary source of lycopene and related carotenoids, may be worthy of clinical trials to assess its health benefits.

The carotenoid values from this study may not be representative for autumn olive fruit collectively. We analyzed a limited number of samples from narrow geographical areas. More comprehensive studies are needed to identify the variation in carotenoid content of autumn olive fruit not only by cultivar, but also under various environmental and growing conditions.

It is notable, however, that this fruit produces unusually high concentrations of lycopene, a carotenoid with potential for protection against some chronic diseases. If, in the future, autumn olive fruit is produced for human consumption, lycopene content could be enhanced by selecting cultivars that excel in lycopene synthesis and/or by hybridizing selected parent plants.

\section{Literature Cited}

Campbell, G.E. and J.O. Dawson. 1989. Growth, yield, and value projections for black walnut interplantings with black alder and autumn olive. Northern J. Appl. For. 6:129-132.

Chug-Ahuja, J.K., J M. Holden, M.R. Forman, A.R. Mangels, G.R. Beecher, and E. Lanza. 1993. The development and application of a carotenoid database for fruits, vegetables, and selected multicomponent foods. J. Amer. Diet. Assoc. 93:318-323.

Clinton, S.K. 1998. Lycopene: Chemistry, biology, and implications for human health and disease. Nutr. Rev. 56:35-51.

Darrow, G. and G.E. Yerkes. 1937. Some unusual opportunities in plant breeding, p. 545-551. In: Unusual bush fruits. Yrbk. Agr., U.S. Dept. Agr.

Dirr, M.A. 1983. Manual of woody landscape plants. Stipes Publ. Co., Champaign, Ill.

Giovannucci, E., A. Ascherio, E.B. Rimm, M.J. Stampfer, G.A. Colditz, and W.C. Willett. 1995. Intake of carotenoids and retinol in relation to risk of prostate cancer. J. Natl. Cancer Inst. 87:1767-1776.

Khachik, F., M.B. Goli, G.R. Beecher, J. Holden, W.R. Lusby, M.D. Tenorio, and M.R. Barrera. 1992. Effect of food preparation on qualitative distribution of major carotenoid constituents of tomatoes and several green vegetables. J. Agr. Food Chem. 40:390-398.

Kohlmeier, L., J.D. Kark, E. Gomez-Garcia, B.C. Martin, S.E. Steck, A.F.M. Kardinaal, J. Ringstad, M. Thamm, V. Masaev, R. Riemersma, J.M. Martin-Moreno, J.K. Huttunen, and F.J. Kok. 1997. Lycopene and myocardial infarction risk in the EURAMIC study. Amer. J.Epidemiol. 146:618-626.

Mangels, A.R., J.M.. Holden, G. R. Beecher, M.R. Forman, and E. Lanza. 1993. Carotenoid content of fruits and vegetables: An evaluation of analytic data. J. Amer. Diet. Assn. 93:284-296.

Parmar, C. and M.K. Kaushal. 1982. Elaeagnus umbellata Thunb. 23-25. In: Wild fruits of the sub-Himalayan region. Kalyani Publ., New Delhi.

Reich, L. 1991. Elaeagnus: Gumi, autumn olive, and Russian olive, p. 113-120. In: Uncommon fruits worthy of attention. Addison-Wesley Publ. Co., Reading, Mass.

Tanaka, T. 1976. Tanaka's cyclopedia of edible plants of the world. Keigaku Publ. Co., Tokyo.

U.S. Dept. of Agriculture, Agr. Res. Serv./Univ. of Minn. Nutr. Coord. Ctr. 1998. USDA-NCC Carotenoid Database for U.S. Foods. Nutrient DataLab. Home Page .http://www.nal.usda.gov/ fnic/food-comp.

Zarger, T.G. 1980. Forestation of surface mines for wildlife. Gen. Tech. Rpt. Northeastern For. Expt. Sta. USDA For. Serv. NE-61:71-74. 